OPEN ACCESS

Edited by:

Moshe Bensimon

Bar-Ilan University, Israel

Reviewed by:

Gerald Cupchik

University of Toronto, Canada

G. Gabrielle Starr,

Pomona College, United States

Helmut Leder,

University of Vienna, Austria

*Correspondence:

Laura M. H. Gallo

lauragallo29@gmail.com

Specialty section:

This article was submitted to

Psychology for Clinical Settings,

a section of the journal

Frontiers in Psychology

Received: 07 January 2021

Accepted: 01 April 2021

Published: 30 April 2021

Citation:

Gallo LMH, Giampietro V

Zunszain PA and Tan KS (2021)

Covid-19 and Mental Health: Could

Visual Art Exposure Help?

Front. Psychol. 12:650314.

doi: 10.3389/fpsyg.2021.650314

\section{Covid-19 and Mental Health: Could Visual Art Exposure Help?}

\author{
Laura M. H. Gallo ${ }^{1 *}$, Vincent Giampietro ${ }^{2}$, Patricia A. Zunszain ${ }^{1}$ and Kai Syng Tan $^{3}$ \\ ${ }^{1}$ Department of Psychological Medicine, Institute of Psychiatry, Psychology and Neuroscience, King's College London, \\ London, United Kingdom, '2Department of Neuroimaging, Institute of Psychiatry, Psychology and Neuroscience, \\ King's College London, London, United Kingdom, ${ }^{3}$ Manchester School of Art, Manchester Metropolitan University, \\ Manchester, United Kingdom
}

A worldwidemental health crisis is expected, as millions worldwide fear death and disease while being forced into repeated isolation. Thus, there is a need for new proactive approaches to improve mental resilience and prevent mental health conditions. Since the 1990s, art has emerged as an alternative mental health therapy in the United States and Europe, becoming part of the social care agenda. This article focuses on how visual esthetic experiences can create similar patterns of neuronal activity as those observed when the reward system is activated. The activation of the reward structures could have a stress buffering effect, given the interdependence observed between the reward and stress systems. Therefore, could visual esthetic experiences stimulate mental resilience? And if this were the case, could art-based interventions be offered for mental health in the context of COVID-19 and beyond?

Keywords: neuroesthetics, reward pathways, mental resilience, fMRI, art

\section{INTRODUCTION}

Isolation, fear, and financial/occupational instability created by the current COVID-19 situation are expected to generate an upsurge in mental illnesses globally (Rajkumar, 2020; Torales et al., 2020). Shortage of mental health workforce and the financial resources needed for traditional interventions are limiting factors to cope effectively with a potential global mental health crisis. United Kingdom research already shows an increase in levels of anxiety, depression, and stress due to current financial challenges (Türközer and Öngür, 2020). This reinforces the urgent need to discover new complementary interventions to help improve low mood and alleviate mental health risks (Holmes et al., 2020).

Just like cognitive behavioral therapy went online to reach more people, equal efforts should be undertaken to deliver art interventions remotely, reaping the benefits of its positive cognitive effects. Here, we discuss how reward brain activation following visual art exposure could promote stress-buffering effects, based on the interdependence observed between the rewards pathway and the sympathetic nervous system. These observations would help to show how visual esthetic experiences could stimulate mental resilience. 


\section{ART ON PRESCRIPTION}

Art interventions have been linked to healing and recovery, influencing mental, somatic, and psychological conditions (Samaritter, 2018; Mastandrea et al., 2019a). This has motivated scientists to study the sensory-emotional values that art can elicit. The first United Kingdom program of arts on prescription was designed in 1994 to help recovery of mild and moderate depression (Bungay and Clift, 2010). Visual art interventions, including painting (Bar-Sela et al., 2007) and collage making (Forzoni et al., 2010) have also been considered helpful by patients suffering from depression or fatigue during chemotherapy treatment.

Assessing the effectiveness of these interventions has been challenging due to a lack of scientific rigor of the rating instruments (Betts, 2006). Nevertheless, a qualitative study of 102 art and mental health projects concluded that art participation enhanced levels of empowerment and was associated to improvements in participants' mental health (Spandler et al., 2007).

Despite a large cohort study suggesting that individuals experiencing depression or anxiety could struggle to engage in art activities (Fancourt and Finn, 2019; Fancourt et al., 2020), a survey conducted by the United Kingdom charity Mind showed that $70 \%$ of service users placed art-based therapies among their top three treatment choices (Parsons et al., 2019). Based on these observations, Parsons et al. (2019) are trialing a combination of mainstream talking therapies and art-based interventions. This mixed approach should help to overcome the limitations of each treatment providing an alternative way to express feelings that may be otherwise difficult or uncomfortable to admit and discuss. Art interventions could be considered as an additional alternative for integrative medicine, becoming a supportive tool in a similar way to mindfulness (Garland et al., 2009; Moss, 2018).

Additionally, a connection between increased art making and neurodegeneration has been reported in Parkinson's disease patients after they started taking dopamine-boosting medication, reinforcing the idea of a relationship between art and the reward system (Canesi et al., 2016). Drawing on these developments, health policy makers are increasingly adopting art-based interventions. Systematic reviews have been conducted using studies from in the United Kingdom, the United States, Netherlands, Sweden, Israel, and France to determine their clinical effectiveness, concluding that art-based therapies are acceptable cost-effective treatments (Reynolds et al., 2000; Leurent et al., 2014; Uttley et al., 2015). Therefore, studying the underlying neural mechanisms of visual art stimulation, which is one focus of the cognitive field of Neuroesthetics, could help us to further understand its benefits.

\section{NEUROESTHETICS: VISUAL ESTHETIC EXPERIENCE}

Neuroesthetics studies (Brown et al., 2011; Skov, 2019) show how the brain reacts to most forms of art (paintings, music, dance, etc.). In the case that interests us here, i.e., visual art, the affective meanings of color, line or shape (effortless unconscious "bottom up" processes) have been found to activate reward system structures (Pelowski et al., 2017). When the art object was associated with a positive social construct (effortful conscious "top down" process), the added "interpretation" further enhanced the esthetic experience (Barry, 2006). Numerous fMRI studies have identified the brain regions associated with perceptual, cognitive, emotional, and reward processing when assessing the beauty of images (Brown et al., 2011; Chatterjee, 2011; Nadal and Skov, 2013; Skov, 2019).

\section{REWARD AREAS ACTIVATED BY ART AND THEIR CONNECTION TO THE STRESS RESPONSIVE SYSTEM}

Viewing paintings generate remarkably similar patterns of brain activity as other pleasurable stimuli, like food, sex, or addictive drugs (Berridge and Kringelbach, 2015). In addition to the basic sensory and social pleasures rewards shared with most animals, humans also have high-order pleasure rewards (Berridge and Kringelbach, 2008). In order to investigate if brain activity could differ between these reward types, Sescousse et al. (2013) compared the brain responses associated with monetary, erotic, and food reward stimuli. They observed that monetary rewards showed higher activation in the orbitofrontal cortex (OFC), compared to the other reward types, indicating that abstract secondary rewards could be associated with more evolved brain regions, which was also the case with art rewards. According to Levy and Glimcher (2012), dissimilar type of rewards can be considered equally desirable for the same individual showing similar OFC activation, supporting the neural common currency hypothesis.

Ultimately, all reward types were associated with a consistent activity increase in the OFC, amygdala, and ventral striatum/ nucleus accumbens (McClure et al., 2004). These are the same brain structures that have been shown to be activated during esthetic experiences (Boccia et al., 2016).

Figure 1 illustrates how brain activation is not limited to the visual and sensorimotor areas but can also engage the reward network through a positive correlation between assigned hedonic value and activation levels in reward areas (Vartanian and Goel, 2004). A meta-analysis comprised of 330 participants conducted by Vartanian and Skov (2014) found that viewing paintings activated the brain's emotion and reward systems in addition to the expected visual cortex. A limitation of these findings could be the prevalence of small sample sizes (mean $22 \pm 4.49$ ). The benefits of art have also been measured through biological parameters of the central nervous system activity. For example, visits to art museums have reported to lower levels of salivary cortisol and self-reported measure of stress (Clow and Fredhoi, 2006) and to decrease systolic blood pressure (Mastandrea et al., 2019b). Taking into consideration the many benefits of art interventions, making them more accessible could be part of the wider strategy of managing mental health risk and treatment. The reward pathway activation observed as a consequence of visual art exposure can be beneficial as 


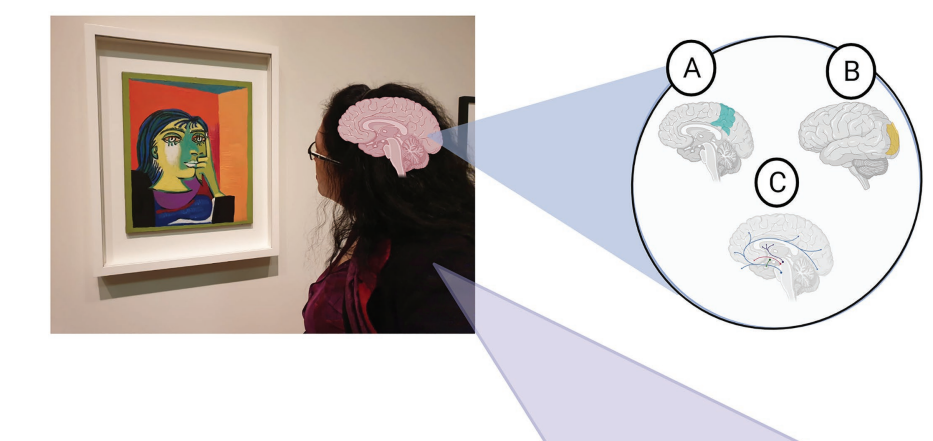

(A) Sensorimotor areas

(B) Visual areas

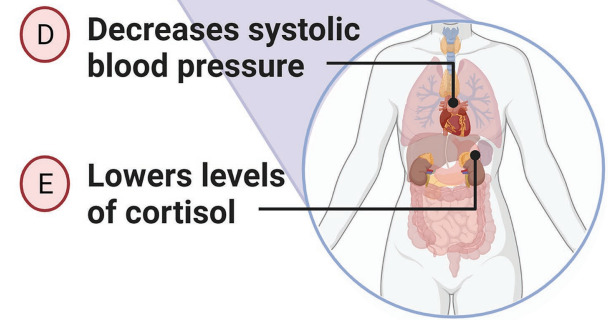

(C) Reward areas

Hedonic values assigned by the viewer to the art stimulus can influence the level of activation of the reward areas

Stress buffering effects reported would reinforce the idea of a connection between the reward and stress system

As COVID-19 financial challenges increase levels of anxiety, depression and stress, more accessible art interventions could help improve low mood while reducing mental health risks.

FIGURE 1 | Schematic diagram for neural activation and stress buffering physical effects of visual art exposure.

reward activation has shown to modulate survival behaviors by reducing stress levels. Even brief exposure to reward stimuli (such as erotic images) can decrease cortisol reactivity, improving cognitive performance on social stress tasks (Creswell et al., 2013).

It is important to note that reward system projections have been linked to regulation of stress response and decreased hypothalamo-pituitary-adrenal response (HPA; Diorio et al., 1993). Dopaminergic neurons of the ventral tegmental area (VTA), which modulates stress vulnerability (Gillies et al., 2014), have dopaminergic connections to the same reward system structures (amygdala, ventral striatum, and OFC) that have been found to become activated by visual art stimuli, which we discuss in more detail below.

\section{The Orbitofrontal Cortex}

The OFC sits within the neocortex and has been associated to emotions, decision making, and rewards processing (Wallis, 2007; Rolls and Grabenhorst, 2008; Bray et al., 2010). Several studies have suggested that the OFC is involved in making esthetic judgments and in conferring hedonic values (Kringelbach, 2005;
Kirk et al., 2009; Huang et al., 2011; Ishizu and Zeki, 2011, 2013; Lacey et al., 2011; Vessel et al., 2012). Furthermore, contextual information might influence the activity observed, as Kirk et al. (2009) found when comparing activation between images labeled as gallery or computer-generated. Gallery labeled images were associated with a significantly higher OFC activation compared to computer labeled images, despite using the same artworks and randomly labeling the images. Nevertheless, some studies with similar designs have failed to observe such OFC activation (Vartanian and Goel, 2004; Cupchik et al., 2009). Lacey et al. (2011) argued that cortical areas adjacent to sinuses, like the OFC, can be susceptible to signal drop-out (Li et al., 1996) which may, in part, explain this inconsistency.

The OFC also makes a significant contribution to the regulation of autonomic stress responses, providing inputs to the hypothalamus (Hostinar et al., 2014). Furthermore, abnormal stress response has been associated with OFC hypoactivation (Holsen et al., 2012). Future studies could investigate if pleasant esthetic experiences help improve this dysregulation. 


\section{The Striatum}

The striatum is composed of three nuclei: ventral striatum (VS), caudate, and putamen (Báez-Mendoza and Schultz, 2013). This brain structure, involved in reward-related processing (Delgado, 2007), was also found to be activated during esthetic experiences. Studies using western art images have reported activation in the VS (Lacey et al., 2011; Vessel et al., 2012), the caudate nucleus (Vartanian and Goel, 2004; Ishizu and Zeki, 2011), and the putamen (Ishizu and Zeki, 2013). Lacey et al. (2011) explored if VS activation could be influenced by artistic status. They paired 50 paintings with "ordinary pictures" that resembled the content and layout of the artwork, finding significantly stronger activation of the VS for art images compared to non-art ones. Likewise, the right caudate nucleus has demonstrated a significant positive correlation between activation level and art image preference. Decreased activation matched lower art ratings, becoming more evident when minimal activation indicated very low rated art (Vartanian and Goel, 2004). Ishizu and Zeki (2013) compared perceptual judgment (brightness) and affective judgment (esthetic) to study if both were recruiting the same brain areas. Participants had to make either an esthetic judgment ("which one is more beautiful?") or a brightness judgment ("which one is brighter?"). Only the esthetic judgment condition showed activation of the basal ganglia, the putamen, and the globus pallidus. Moreover, it has been shown that changes in reinforcement events, such as having fulfilling relationships or feeling productive, lead to decreased energy and mood and can conduce to abnormal ventral striatum functional connectivity, which has been found to be a predictor of depressive disorder risk (Pan et al., 2017). Considering the rewarding aspect of esthetic experiences, art consumption could constitute a self-sustained reinforcement event to help with low mood and reduce the risk of abnormal functional connectivity.

\section{The Amygdala}

Although the amygdala has been consistently associated with emotions, especially fear conditioning (Krabbe et al., 2018), it has also been shown to be associated with reward related learning. A rodent study has observed amygdala involvement in updating reward value (Chesworth and Corbit, 2017) and this brain area was also shown to be involved in experiences of pleasure or disgust when assessing facial attractiveness in humans (Winston et al., 2007). Signal drop-out due to magnetic inhomogeneity and low signal-to-noise ratio in this region might be a reason for which neuroesthetic studies do not consistently report activation in the amygdala (Boubela et al., 2015). Another explanation could be that the amygdala is implicated in esthetic or affective judgment (Wagar and Thagard, 2004), rather than in simply viewing the art. It is worth noting that the neuroesthetic studies reporting amygdala activation included such judgment tasks (Ishizu and Zeki, 2011, 2013; Jacobs et al., 2016) which were not included in those studies that did not report amygdala activation.

The amygdala has also been shown to be recruited in several tasks that require emotional decision-making, such as expression and perception of fear, appetitive processes, or social judgments, and it is part of the stress-response system (Drevets, 2003). Mood disorders, like major depression or bipolar disorder have been associated with elevated resting cerebral blood flow in this region, with downregulation depending on cognitive control areas, like the OFC, to reappraise contextual value (Dolan, 2007). In essence, the role of the amygdala in emotional regulation, which has been extensively studied, might explain its involvement during esthetic judgments, as subjective preferences are mostly based upon emotional responses.

\section{DISCUSSION}

As the COVID-19 variants threaten to extend the duration of this pandemic, the widespread emotional distress increases the risk for psychiatric illness. In light of this potential mental health crisis, which is even affecting the health workforce, new self-help tools to enhance mental resilience need to be identified and implemented. As explained above, there is enough evidence to suggest that art interventions can support mental health recovery, thanks to its emotionally charged rewarding nature.

Translational and human research has consistently shown that increased reward manipulations and rewarding environments promote the growth of stress resilience (Dutcher and Creswell, 2018). Much of this research has analyzed the stress buffering effects of primary rewards using food, drink, or sex (Abad et al., 1996; Christiansen et al., 2011; Creswell et al., 2013). However, there is also emerging evidence that visual art interventions can enhance functional connectivity related to psychological resilience (Bolwerk et al., 2014), can lower levels of salivary cortisol and of self-reported measure of stress (Clow and Fredhoi, 2006) and even decrease systolic blood pressure (Mastandrea et al., 2019b).

Examples of association between the reward and stress systems have been documented, such as in the animal and human findings on how psychological stress can affect eating behavior (Levine and Morley, 1981; Morley et al., 1983; Adam and Epel, 2007) or how environmental stressors can decrease reward-seeking behavior leading to anhedonia (Stanton et al., 2019). Stress responses regulated by the HPA system control body peripheral functions, like metabolism and immunity, while having an intense effect on the brain (Pariante and Lightman, 2008). For example, the hypothalamus has GABAergic connections to the reward system, connecting to the Ventral Striatum (Russo and Nestler, 2013), reinforcing the idea that reward and stress systems are linked. Resilient special forces soldiers revealed unique activation patterns during anticipation of reward (Vythilingam et al., 2009), while a large fMRI study suggested that resilience to adversity was correlated with increased dopaminergic activity in the VTA and hippocampus (Richter et al., 2019).

The close relationship between these systems could explain how art that stimulates our reward system (Nadal, 2013) can promote well-being, social inclusion and support mental health recovery and resilience. Art can help express complex feelings 
or sensations, avoiding verbal interpretations while allowing for diversion and emotional escape, as has been shown, even during extremely challenging situations, like imprisonment (Gussak, 2007). Given the psychological parallels that can be drawn between imprisonment and COVID-19 lockdown policies (Dhami et al., 2020), art could also, therefore, provide a coping mechanism to counter the negative consequences of this form of confinement.

On the basis of the evidence presented here, we recommend that resources can be allocated for new online art therapy treatment for psychological stress and low mood to improve

\section{REFERENCES}

Abad, F., Diaz, N. M., Domenech, E., Robayna, M., and Rico, J. (1996). Oral sweet solution reduces pain-related behaviour in preterm infants. Acta Paediatr. 85, 854-858. doi: 10.1111/j.1651-2227.1996.tb14167.x

Adam, T. C., and Epel, E. S. (2007). Stress, eating and the reward system. Physiol. Behav. 91, 449-458. doi: 10.1016/j.physbeh.2007.04.011

Báez-Mendoza, R., and Schultz, W. (2013). The role of the striatum in social behavior. Front. Neurosci. 7:233. doi: 10.3389/fnins.2013.00233

Barry, A. M. (2006). Perceptual aesthetics: transcendent emotion, neurological image. Vis. Commun. Q. 13, 134-151. doi: 10.1207/s15551407vcq1303_2

Bar-Sela, G., Atid, L., Danos, S., Gabay, N., and Epelbaum, R. (2007). Art therapy improved depression and influenced fatigue levels in cancer patients on chemotherapy. Psychooncology 16, 980-984. doi: 10.1002/ pon. 1175

Berridge, K. C., and Kringelbach, M. L. (2008). Affective neuroscience of pleasure: reward in humans and animals. Psychopharmacology 199, 457-480. doi: $10.1007 /$ s00213-008-1099-6

Berridge, K. C., and Kringelbach, M. L. (2015). Pleasure systems in the brain. Neuron 86, 646-664. doi: 10.1016/j.neuron.2015.02.018

Betts, D. J. (2006). Art therapy assessments and rating instruments: do they measure up? Arts Psychother. 33, 422-434. doi: 10.1016/j.aip.2006.08.001

Boccia, M., Barbetti, S., Piccardi, L., Guariglia, C., Ferlazzo, F., Giannini, A. M., et al. (2016). Where does brain neural activation in aesthetic responses to visual art occur? Meta-analytic evidence from neuroimaging studies. Neurosci. Biobehav. Rev. 60, 65-71. doi: 10.1016/j.neubiorev.2015.09.009

Bolwerk, A., Mack-Andrick, J., Lang, F. R., Dörfler, A., and Maihöfner, C. (2014). How art changes your brain: differential effects of visual art production and cognitive art evaluation on functional brain connectivity. PLoS One 9:e101035. doi: 10.1371/journal.pone.0101035

Boubela, R. N., Kalcher, K., Huf, W., Seidel, E. M., Derntl, B., Pezawas, L., et al. (2015). fMRI measurements of amygdala activation are confounded by stimulus correlated signal fluctuation in nearby veins draining distant brain regions. Sci. Rep. 5:10499. doi: 10.1038/srep10499

Bray, S., Shimojo, S., and O’Doherty, J. P. (2010). Human medial orbitofrontal cortex is recruited during experience of imagined and real rewards. J. Neurophysiol. 103, 2506-2512. doi: 10.1152/jn.01030.2009

Brown, S., Gao, X., Tisdelle, L., Eickhoff, S. B., and Liotti, M. (2011). Naturalizing aesthetics: brain areas for aesthetic appraisal across sensory modalities. NeuroImage 58, 250-258. doi: 10.1016/j.neuroimage.2011.06.012

Bungay, H., and Clift, S. (2010). Arts on prescription: a review of practice in the UK. Perspect. Public Health 130, 277-281. doi: 10.1177/1757913910384050

Canesi, M., Rusconi, M. L., Moroni, F., Ranghetti, A., Cereda, E., and Pezzoli, G. (2016). Creative thinking, professional artists, and Parkinson's disease. J. Parkinsons Dis. 6, 239-246. doi: 10.3233/JPD-150681

Chatterjee, A. (2011). Neuroaesthetics: a coming of age story. J. Cogn. Neurosci. 23, 53-62. doi: 10.1162/jocn.2010.21457

Chesworth, R., and Corbit, L. (2017). "The Contribution of the Amygdala to RewardRelated Learning and Extinction," in The Amygdala-Where Emotions Shape Perception, Learning and Memories. Vol. 1. ed. B. Ferry (Books on Demand), 13.

Christiansen, A. M., Dekloet, A. D., Ulrich-Lai, Y. M., and Herman, J. P. (2011). "Snacking" causes long term attenuation of HPA axis stress responses the general population's mental well-being and resilience, which is especially important in this time of crisis while the researchers are still assessing the psychological impact of the COVID-19 crisis.

\section{AUTHOR CONTRIBUTIONS}

This opinion article was conceived and processed into the manuscript by LG under supervision of VG, PZ, and KT. All authors critically appraised the intellectual content and structure of this manuscript and approved the final version. and enhancement of brain FosB/deltaFosB expression in rats. Physiol. Behav 103, 111-116. doi: 10.1016/j.physbeh.2011.01.015

Clow, A., and Fredhoi, C. (2006). Normalisation of salivary cortisol levels and self-report stress by a brief lunchtime visit to an art gallery by London City workers. J. Holist. Healthc. 3, 29-32.

Creswell, J. D., Pacilio, L. E., Denson, T. F., and Satyshur, M. (2013). Experimental manipulation of primary sexual reward buffers cortisol responses to psychosocial stress in men. Psychosom. Med. 75, 1-7. doi: 10.1097/PSY.0b013e31828c4524

Cupchik, G. C., Vartanian, O., Crawley, A., and Mikulis, D. J. (2009). Viewing artworks: contributions of cognitive control and perceptual facilitation to aesthetic experience. Brain Cogn. 70, 84-91. doi: 10.1016/j.bandc.2009.01.003

Delgado, M. R. (2007). Reward-related responses in the human striatum. Ann. N. Y. Acad. Sci. 1104, 70-88. doi: 10.1196/annals.1390.002

Dhami, M. K., Weiss-Cohen, L., and Ayton, P. (2020). Are people experiencing the 'pains of imprisonment' during the Covid-19 lockdown? Front. Psychol. 11:3179. doi: 10.3389/fpsyg.2020.578430

Diorio, D., Viau, V., and Meaney, M. J. (1993). The role of the medial prefrontal cortex (cingulate gyrus) in the regulation of hypothalamic-pituitary-adrenal responses to stress. J. Neurosci. 13, 3839-3847. doi: 10.1523/JNEUROSCI.1309-03839.1993

Dolan, R. J. (2007). The human amygdala and orbital prefrontal cortex in behavioural regulation. Philos. Trans. R. Soc. Lond. Ser. B Biol. Sci. 362, 787-799. doi: $10.1098 /$ rstb.2007.2088

Drevets, W. C. (2003). Neuroimaging abnormalities in the amygdala in mood disorders. Ann. N. Y. Acad. Sci. 985, 420-444. doi: 10.1111/j.1749-6632.2003. tb07098.x

Dutcher, J. M., and Creswell, J. D. (2018). The role of brain reward pathways in stress resilience and health. Neurosci. Biobehav. Rev. 95, 559-567. doi 10.1016/j.neubiorev.2018.10.014

Fancourt, D., Baxter, L., and Lorencatto, F. (2020). Barriers and enablers to engagement in participatory arts activities amongst individuals with depression and anxiety: quantitative analyses using a behaviour change framework. BMC Public Health 20:272. doi: 10.1186/s12889-020-8337-1

Fancourt, D., and Finn, S. (2019). Cultural Contexts of Health: The Role of the Arts in Improving Health and Well-Being in the WHO European Region. Copenhagen: World Health Organisation.

Forzoni, S., Perez, M., Martignetti, A., and Crispino, S. (2010). Art therapy with cancer patients during chemotherapy sessions: an analysis of the patients' perception of helpfulness. Palliat. Support. care 8:41. doi: 10.1017/S1478951509990691

Garland, E., Gaylord, S., and Park, J. (2009). The role of mindfulness in positive reappraisal. Explore 5, 37-44. doi: 10.1016/j.explore.2008.10.001

Gillies, G. E., Virdee, K., McArthur, S., and Dalley, J. W. (2014). Sex-dependent diversity in ventral tegmental dopaminergic neurons and developmental programing: a molecular, cellular and behavioral analysis. Neuroscience 282, 69-85. doi: 10.1016/j.neuroscience.2014.05.033

Gussak, D. (2007). The effectiveness of art therapy in reducing depression in prison populations. Int. J. Offender Ther. Comp. Criminol. 51, 444-460. doi: 10.1177/0306624X06294137

Holmes, E. A., O'Connor, R. C., Perry, V. H., Tracey, I., Wessely, S., Arseneault, L., et al. (2020). Multidisciplinary research priorities for the COVID-19 pandemic: a call for action for mental health science. Lancet Psychiatry 7, 547-560. doi: 10.1016/S2215-0366(20)30168-1 
Holsen, L. M., Lee, J. H., Spaeth, S. B., Ogden, L. A., Klibanski, A., Whitfield-Gabrieli, S., et al. (2012). Brain hypoactivation, autonomic nervous system dysregulation, and gonadal hormones in depression: a preliminary study. Neurosci. Lett. 514, 57-61. doi: 10.1016/j.neulet.2012.02.056

Hostinar, C. E., Sullivan, R. M., and Gunnar, M. R. (2014). Psychobiological mechanisms underlying the social buffering of the HPA axis: a review of animal models and human studies across development. Psychol. Bull. 140, 256-282. doi: 10.1037/a0032671

Huang, M., Bridge, H., Kemp, M. J., and Parker, A. J. (2011). Human cortical activity evoked by the assignment of authenticity when viewing works of art. Front. Hum. Neurosci. 5:134. doi: 10.3389/fnhum.2011.00134

Ishizu, T., and Zeki, S. (2011). Toward a brain-based theory of beauty. PLoS One 6:e21852. doi: 10.1371/journal.pone.0021852

Ishizu, T., and Zeki, S. (2013). The brain's specialized systems for aesthetic and perceptual judgment. Eur. J. Neurosci. 37, 1413-1420. doi: 10.1111/ ejn. 12135

Jacobs, R. H., Haak, K. V., Thumfart, S., Renken, R., Henson, B., and Cornelissen, F. W. (2016). Aesthetics by numbers: links between perceived texture qualities and computed visual texture properties. Front. Hum. Neurosci. 10:343. doi: $10.3389 /$ fnhum. 2016.00343

Kirk, U., Skov, M., Hulme, O., Christensen, M. S., and Zeki, S. (2009). Modulation of aesthetic value by semantic context: an fMRI study. NeuroImage 44, 1125-1132. doi: 10.1016/j.neuroimage.2008.10.009

Krabbe, S., Gründemann, J., and Lüthi, A. (2018). Amygdala inhibitory circuits regulate associative fear conditioning. Biol. Psychiatry 83, 800-809. doi: 10.1016/j.biopsych.2017.10.006

Kringelbach, M. L. (2005). The human orbitofrontal cortex: linking reward to hedonic experience. Nat. Rev. Neurosci. 6, 691-702. doi: 10.1038/nrn1747

Lacey, S., Hagtvedt, H., Patrick, V. M., Anderson, A., Stilla, R., Deshpande, G., et al. (2011). Art for reward's sake: visual art recruits the ventral striatum. NeuroImage 55, 420-433. doi: 10.1016/j.neuroimage.2010.11.027

Leurent, B., Killaspy, H., Osborn, D. P., Crawford, M. J., Hoadley, A., Waller, D., et al. (2014). Moderating factors for the effectiveness of group art therapy for schizophrenia: secondary analysis of data from the MATISSE randomised controlled trial. Soc. Psychiatry Psychiatr. Epidemiol. 49, 1703-1710. doi: 10.1007/s00127-014-0876-2

Levine, A. S., and Morley, J. E. (1981). Stress-induced eating in rats. Am. J. Phys. 241, R72-R76. doi: 10.1152/ajpregu.1981.241.1.R72

Levy, D. J., and Glimcher, P. W. (2012). The root of all value: a neural common currency for choice. Curr. Opin. Neurobiol. 22, 1027-1038. doi: 10.1016/j. conb.2012.06.001

Li, S., Dardzinski, B. J., Collins, C. M., Yang, Q. X., and Smith, M. B. (1996). Three-dimensional mapping of the static magnetic field inside the human head. Magn. Reson. Med. 36, 705-714. doi: 10.1002/mrm.1910360509

Mastandrea, S., Fagioli, S., and Biasi, V. (2019a). Art and psychological wellbeing: linking the brain to the aesthetic emotion. Front. Psychol. 10:739. doi: $10.3389 /$ fpsyg.2019.00739

Mastandrea, S., Maricchiolo, F., Carrus, G., Giovannelli, I., Giuliani, V., and Berardi, D. (2019b). Visits to figurative art museums may lower blood pressure and stress. Arts Health 11, 123-132. doi: 10.1080/17533015.2018.1443953

McClure, S. M., York, M. K., and Montague, P. R. (2004). The neural substrates of reward processing in humans: the modern role of FMRI. Neuroscientist 10, 260-268. doi: 10.1177/1073858404263526

Morley, J. E., Levine, A. S., and Rowland, N. E. (1983). Minireview. Stress induced eating. Life Sci. 32, 2169-2182. doi: 10.1016/0024-3205(83)90415-0

Moss, D. (2018). The role of mindfulness approaches in integrative medicine. Biofeedback 46, 9-14. doi: 10.5298/1081-5937-46.1.03

Nadal, M. (2013). "The Experience of Art: Insights From Neuroimaging," in Progress in Brain Research. Vol. 204. Elsevier, 135-158.

Nadal, M., and Skov, M. (2013). Introduction to the special issue: toward an interdisciplinary neuroaesthetics. Psychol. Aesthet. Creat. Arts 7:1. doi: 10.1037/ a0031842

Pan, P. M., Sato, J. R., Salum, G. A., Rohde, L. A., Gadelha, A., Zugman, A., et al. (2017). Ventral striatum functional connectivity as a predictor of adolescent depressive disorder in a longitudinal community-based sample. Am. J. Psychiatr. 174, 1112-1119. doi: 10.1176/appi.ajp.2017.17040430

Pariante, C. M., and Lightman, S. L. (2008). The HPA axis in major depression: classical theories and new developments. Trends Neurosci. 31, 464-468. doi: 10.1016/j.tins.2008.06.006
Parsons, A., Omylinska-Thurston, J., Karkou, V., Harlow, J., Haslam, S., Hobson, J., et al. (2019). Arts for the blues-a new creative psychological therapy for depression. Br. J. Guid. Couns. 48, 1-16. doi: 10.1080/03069885.2019.1633459

Pelowski, M., Markey, P. S., Forster, M., Gerger, G., and Leder, H. (2017). Move me, astonish me... delight my eyes and brain: The Vienna integrated model of top-down and bottom-up processes in art perception (VIMAP) and corresponding affective, evaluative, and neurophysiological correlates. Phys Life Rev 21, 80-125. doi: 10.1016/j.plrev.2017.02.003

Rajkumar, R. P. (2020). COVID-19 and mental health: a review of the existing literature. Asian J. Psychiatr. 52:102066. doi: 10.1016/j.ajp.2020.102066

Reynolds, M. W., Nabors, L., and Quinlan, A. (2000). The effectiveness of art therapy: does it work? Art Ther. 17, 207-213. doi: 10.1080/07421656.2000.10129706

Richter, A., Krämer, B., Diekhof, E. K., and Gruber, O. (2019). Resilience to adversity is associated with increased activity and connectivity in the VTA and hippocampus. Neuroimage Clin. 23:101920. doi: 10.1016/j.nicl.2019.101920

Rolls, E. T., and Grabenhorst, F. (2008). The orbitofrontal cortex and beyond: from affect to decision-making. Prog. Neurobiol. 86, 216-244. doi: 10.1016/j. pneurobio.2008.09.001

Russo, S. J., and Nestler, E. J. (2013). The brain reward circuitry in mood disorders. Nat. Rev. Neurosci. 14, 609-625. doi: 10.1038/nrn3381

Samaritter, R. (2018). The aesthetic turn in mental health: reflections on an explorative study into practices in the arts therapies. Behav. Sci. 8:41. doi: 10.3390/bs8040041

Sescousse, G., Caldú, X., Segura, B., and Dreher, J. C. (2013). Processing of primary and secondary rewards: a quantitative meta-analysis and review of human functional neuroimaging studies. Neurosci. Biobehav. Rev. 37, 681-696. doi: 10.1016/j.neubiorev.2013.02.002

Skov, M. (2019). Aesthetic appreciation: the view from neuroimaging. Empir. Stud. Arts 37, 220-248. doi: 10.1177/0276237419839257

Spandler, H., Secker, J., Hacking, S., Kent, L., and Shenton, J. (2007). Mental health, social inclusion and arts: developing the evidence base. Available at: http://clok.uclan.ac.uk/3846/1/Arts.MH.FinalReportforweb.pdf (Accessed April 01, 2021).

Stanton, C. H., Holmes, A. J., Chang, S. W., and Joormann, J. (2019). From stress to anhedonia: molecular processes through functional circuits. Trends Neurosci. 42, 23-42. doi: 10.1016/j.tins.2018.09.008

Torales, J., O'Higgins, M., Castaldelli-Maia, J. M., and Ventriglio, A. (2020). The outbreak of COVID-19 coronavirus and its impact on global mental health. Int. J. Soc. Psychiatry 66, 317-320. doi: 10.1177/0020764020915212

Türközer, H. B., and Öngür, D. (2020). A projection for psychiatry in the post-COVID-19 era: potential trends, challenges, and directions. Mol. Psychiatry 25, 2214-2219. doi: 10.1038/s41380-020-0841-2

Uttley, L., Scope, A., Stevenson, M., Rawdin, A., Buck, E. T., Sutton, A., et al. (2015). Systematic review and economic modelling of the clinical effectiveness and cost-effectiveness of art therapy among people with non-psychotic mental health disorders. Health Technol. Assess. 19, 1-120. doi: 10.3310/hta19180

Vartanian, O., and Goel, V. (2004). Neuroanatomical correlates of aesthetic preference for paintings. Neuroreport 15, 893-897. doi: 10.1097/00001756-200404090-00032

Vartanian, O., and Skov, M. (2014). Neural correlates of viewing paintings: evidence from a quantitative meta-analysis of functional magnetic resonance imaging data. Brain Cogn. 87, 52-56. doi: 10.1016/j.bandc.2014.03.004

Vessel, E. A., Starr, G. G., and Rubin, N. (2012). The brain on art: intense aesthetic experience activates the default mode network. Front. Hum. Neurosci. 6:66. doi: $10.3389 /$ fnhum.2012.00066

Vythilingam, M., Nelson, E. E., Scaramozza, M., Waldeck, T., Hazlett, G., Southwick, S. M., et al. (2009). Reward circuitry in resilience to severe trauma: an fMRI investigation of resilient special forces soldiers. Psychiatry Res. Neuroimaging 172, 75-77. doi: 10.1016/j.pscychresns.2008.06.008

Wagar, B. M., and Thagard, P. (2004). Spiking Phineas Gage: a neurocomputational theory of cognitive-affective integration in decision making. Psychol. Rev. 111:67. doi: 10.1037/0033-295X.111.1.67

Wallis, J. D. (2007). Orbitofrontal cortex and its contribution to decision-making. Annu. Rev. Neurosci. 30, 31-56. doi: 10.1146/annurev.neuro.30.051606.094334

Winston, J. S., O’Doherty, J., Kilner, J. M., Perrett, D. I., and Dolan, R. J. (2007). Brain systems for assessing facial attractiveness. Neuropsychologia 45, 195-206. doi: 10.1016/j.neuropsychologia.2006.05.009

Conflict of Interest: The authors declare that the research was conducted in the absence of any commercial or financial relationships that could be construed as a potential conflict of interest. 
Copyright (c) 2021 Gallo, Giampietro, Zunszain and Tan. This is an open-access article distributed under the terms of the Creative Commons Attribution License (CC BY). The use, distribution or reproduction in other forums is permitted, provided the original author(s) and the copyright owner(s) are credited and that the original publication in this journal is cited, in accordance with accepted academic practice. No use, distribution or reproduction is permitted which does not comply with these terms. 